\title{
Contemporary Creativity Research in Taiwan: A Critical Review
}

\author{
Kuan Chen Tsai \\ Faculty of Humanities and Social Science, City University of Macau \\ 81-121 Av. Xian Xing Hai, Golden Dragon Centre, 19 Andares, Macau \\ E-mail: tsaikuanchen@cityu.edu.mo
}

Received: October 7, 2014 Accepted: November 23, 2014 Published: November 25, 2014

doi:10.5296/ijch.v1i2.6416 URL: http://dx.doi.org/10.5296/ijch.v1i2.6416

\begin{abstract}
The value of creativity in educational and organizational contexts has achieved widespread recognition in Taiwanese society over the last decade. The present study utilizes it to examine doctoral dissertations related to the topic of creativity in Taiwan, with the wider aim of understanding the attitudes of researchers and possible trends in the Taiwanese creativity research community. Major findings from this meta-analytic study indicate that creativity might serve to maximize both students' learning performance, and organizational survival. This study also has made it clear that creativity is an important phenomenon across different disciplines in the community of Taiwanese doctoral researchers. It is hoped that this article's examination of Taiwanese dissertations will stimulate other investigators to conduct in-depth studies for the better understanding of local creativity development and related issues.
\end{abstract}

Keywords: Creativity, Meta-analytic study, Taiwanese dissertations

\section{Introduction}

It is widely believed that creativity offers a channel for coping effectively with major life changes, especially age-related physiological and functional declines (Flood \& Scharer, 2006). Specifically, modern challenges necessitate the adoption of a new way of thinking, in which creative problem-finding and problem-solving play a key role (Fontenot, 1993). The stimulation of creativity in individuals improves their functioning at all levels (Sierpina \& Cole, 2004). A large number of empirical studies (e.g., Moneta, Amabile, Schatzel, \& Kramer, 2010; Okuda, Runco, \& Berger, 1991; Torrance \& Presbury, 1984; Zhou \& George, 2001) confirm the strong relationship between creative activities and individual performance, either in school or in organizations. Their findings indicate that creative activity encourages a sense of competence, purpose, and growth, since "adaptability, flexibility, and coping are inherent 
in the creative process" (Fisher \& Specht, 1999, p. 459). As a result, such activity contributes to well-being in all aspects of life.

The Taiwanese Ministry of Education's (2002) white paper on creative education argues that only by developing creativity and innovation can the knowledge quality of the Taiwanese population be improved. In other words, promoting creative education is seen as a necessity for confronting the era of the knowledge economy. There are five core values discussed in this white paper: (a) cultivating the attitude of lifelong learning, (b) respecting individual difference, (c) accumulating accessible knowledge capital, (d) constructing knowledge-based creative industries, and (e) fostering a diverse and innovative culture. It would appear that Taiwan's government seriously contemplates constructing a creative nation via five levels: the individual, schooling, society, industry, and culture. The value of creativity in educational and organizational contexts has achieved widespread recognition in Taiwanese society over the last decade, as evidenced by the establishment of several graduate-level academic programs focused on creativity and innovation, the emergence of national creativity contests, and the discussion of creative thinking in seminars and conferences.

Magyari-Beck (1990) has proposed a useful taxonomy for the meta-analytical study of creativity. This classifies creativity research via a matrix that specifies three dimensions: the aspect on which the study focuses, the level at which it is investigated, and the approach used by the researcher. The aspects of creativity are further divided into traits, processes, and products, and the investigated levels into individual, group, organization, and culture. Finally, research approaches are viewed in two parts-research background and research analysis - which yields four groups: empirical qualitative, empirical quantitative, theoretical qualitative, and theoretical quantitative. To our knowledge, two studies have utilized this typology: the first was Wehner, Csikszentmihalyi, and Magyari-Beck's (1991) study of the U.S. Dissertation Abstracts web in 1986; almost two decades later, Kahl, da Fonseca, and Witte (2009) used the same database as the previous study. Taken together, these studies make it clear that the research focus on individual creativity has been and remains the most popular, whereas one can discern a decreasing trend in creativity research on the cultural level.

My own review of the relevant literature suggests that, Magyari-Beck's (1991) typology of creativity is an appropriate tool with which to classify possible trends in creativity research. Thus, the present study utilizes it to examine doctoral dissertations related to the topic of creativity in Taiwan, with the wider aim of understanding the attitudes of researchers and possible trends in the Taiwanese creativity research community. The rationale for the use of the dissertation as a unit of analysis is that "dissertations give a better indication than current publications of where a domain is going, because the work of the current graduates is going to shape the publications of the future" (Wehner et al., 1991, pp. 261-262).

\section{Method}

\subsection{Literature Identification}

Data were collected from the online National Digital Library of Theses and Dissertations in Taiwan (NDLTD; http://ndltd.ncl.edu.tw/). All data retrieved were dissertations published in 
NDLTD between 2003 and 2013. This relatively brief period was chosen in order to ensure the contemporary nature of the surveyed research on creativity in Taiwan. Search terms in the current study were "creativity," "creative thinking," and "creative," which are also commonly used in other meta-analytic studies (e.g., Ma, 2006; Scott, Leritz, \& Mumford, 2004). The initial retrieval yielded more than 400 abstracts. A sampling procedure was therefore used to identify the more relevant dissertations: if a particular dissertation's keywords or title did not include any of the three search terms, that dissertation was excluded from the sample. Following this procedure, a total of 85 Chinese-language dissertations remained for further analysis.

\subsection{Coding}

After the relevant dissertations were selected, each was coded as follows: (a) author, (b) title, (c) date of publication, (d) discipline, (e) abstract, (f) typology, and (g) key words provided by the author(s). In Taiwan, all dissertations are required to include an English-language version of the abstract, and these were used for coding in the current study. All of the coding was first keyed in Microsoft Excel and then transformed to HyerRESEARCH 3.5 (2013) for further data analysis. In addition, each abstract was coded using Magyari-Beck's (1990) typology of creativity research, as more fully described in the Introduction section, above. The coding scheme of each Magyari-Beck sub-category was modified according to the suggestions provided by Kahl et al. (2009, pp. 2-3).

\subsection{Data Analysis}

In addition to typological classification, all abstracts were subjected to a qualitative analysis method in order to investigate possible themes within this dataset. According to Leech and Onwuegbuzie (2007), a number of qualitative techniques are useful for analyzing qualitative data. For the current study, three were implemented: (a) keywords-in-context, whereby any terminology associated with creativity was identified, to serve as the springboard for the development of themes; (b) word counting, meaning that each word appearing in the abstracts was assessed for the frequency with which it was used in the sample as a whole; and (c) classical content analysis, in which the number of occurrences of each code was counted in order to discern the important concepts in the descriptions (for more detail, see Leech \& Onwuegbuzie, 2007, pp. 566-570).

\section{Results}

The application of Magyari-Beck's (1990) typology, as shown in Table 1, indicates that in the 'aspects' dimension, the most-studied topic was the creative process $(72 \%)$ and the least-studied was traits $(11 \%)$. In the 'levels' dimension, researchers placed the most emphasis on individual' creativity (57\%), which was more than four times more popular as a topic than either group creativity (13\%) or organizational creativity (also 13\%). 


\section{Ml Macrothink}

Table 1. Observed frequencies and percentages for the entire sample $(\mathrm{N}=85)$ across aspect and level dimensions

\begin{tabular}{|l|l|l|l|l|}
\hline & \multicolumn{4}{c|}{ Aspects } \\
\hline Levels & \multicolumn{1}{|c|}{ Traits } & \multicolumn{1}{c|}{ Processes } & \multicolumn{1}{c|}{ Products } & \multicolumn{1}{c|}{ All } \\
\hline Individual & 8 & 36 & 7 & $49(57 \%)$ \\
\hline Group & 0 & 9 & 1 & $11(13 \%)$ \\
\hline Organization & 1 & 8 & 1 & $10(13 \%)$ \\
\hline Culture & 0 & 8 & 6 & $14(17 \%)$ \\
\hline All & $9(11 \%)$ & $61(72 \%)$ & $15(17 \%)$ & $85(100 \%)$ \\
\hline
\end{tabular}

It also emerged that quantitative and qualitative approaches received an equal amount of attention, as shown in Table 2. Empirical quantitative methods were the most popular with doctoral researchers $(40 \%)$, while empirical qualitative methods were the least likely to be chosen (10\%). As far as discipline was concerned, the largest number of dissertations were in the field of education (29\%), followed by business administration and economics $(21 \%)$, the social sciences (16\%) and of art and design (also 16\%). Interestingly, psychology was ranked near the bottom of this list.

Table 2. The distribution of research approaches, disciplines, and keywords related to creativity in the sample of 85 abstracts

\begin{tabular}{|c|c|c|}
\hline Category & $n$ & $\%$ \\
\hline \multicolumn{3}{|c|}{ Research approaches } \\
\hline Empirical qualitative & 8 & 10 \\
\hline Empirical quantitative & 34 & 40 \\
\hline Theoretical qualitative & 20 & 23 \\
\hline Theoretical quantitative & 23 & 27 \\
\hline \multicolumn{3}{|c|}{ Disciplines } \\
\hline Education & 25 & 29 \\
\hline Business \& economics & 18 & 21 \\
\hline Social sciences & 14 & 16 \\
\hline Art \& design & 13 & 16 \\
\hline Sciences \& engineering & 7 & 8 \\
\hline Psychology & 4 & 5 \\
\hline Others & 4 & 5 \\
\hline \multicolumn{3}{|c|}{ Word count $(n)$} \\
\hline Creativity & 472 & \\
\hline Creative & 451 & \\
\hline Innovation & 85 & \\
\hline Flexibility & 25 & \\
\hline Fluency & 21 & \\
\hline Divergent & 17 & \\
\hline Innovative & 17 & \\
\hline Originality & 15 & \\
\hline Create & 17 & \\
\hline Elaboration & 11 & \\
\hline
\end{tabular}




\section{$\triangle$ Macrothink}

The qualitative analysis of the current dataset was conducted from three perspectives. First, words associated with creativity were counted and the results show the noun "creativity" and adjective "creative" occurred more than 400 times in this dataset (see Table 2). The term "innovation" appeared 85 times, while somewhat surprisingly, "originality" only occurred 15 times. Four terms commonly used to describe key elements of creative thinking-fluency, flexibility, originality, and elaboration - each appeared less than 30 times.

When scrutinizing all 85 abstracts, a number of keywords denoting the idea of creativity were found to have been used by researchers. Among these, "creative industry", "creative thinking", "innovation", and "problem solving" were the most common. However, a wide range of other terms were used, or coined, by the authors, including "cross-border thinking", "creativity power", "creativity class", "creative space", and "creative platform".

Two major themes surfaced in this corpus: a) the benefits of creativity for learning and thinking, and (b) the important role of creativity in industrial development and innovation. The first theme mainly emerges from the fields of education, art, and psychology, as part of an examination of the correlation between creativity and other variables, or of the effects of creativity-training on other expected learning outcomes. Keywords that appeared repeatedly in these dissertations, included "problem solving", "creative teaching", "creative thinking", "creative learning", "creative curriculum", and "creativity education", an indication that researchers are investigating creativity from the perspectives of learners, educators, curricula, policy-making, and educational frameworks. Overall, they found positive effects of creativity on cognition and affect in individuals ranging from elementary school students to adult learners. Therefore, they suggest that from the viewpoint of pedagogy, the idea of creativity could be included in curriculum- and program development, thereby boosting leaning, increasing self-efficacy, and making students' learning journey smoother.

The second theme is mostly derived from business studies and the social sciences. From the perspective of organizational behavior, several studies examined the effects of creativity upon employees, teams, and whole organizations. They found that creative personality among individual coworkers, creativity in teams, and the attitude toward creativity from supervisors and the organization functioned as important predictors of organizational well-being and, ultimately, survival. Their arguments are rooted in the principle of the modern business jungle - if you do not adapt, you will be eaten-which implies that equipping itself with creativity is a prerequisite for any company to become successful. In addition, some studies discussed the development of creative industries in Taiwan, and argued that the country's unique cultures of local communities should be taken into consideration, especially in light of the influence of globalization. In other words, they suggest that the government ponder how to enact useful and effective laws and policies to support and protect Taiwanese creative industries.

\section{Discussion}

Before discussing the major findings of the present study, it is important to be aware of some of its limitations. Its focus was on contemporary perspectives on creativity in the community of Taiwanese doctoral researchers, so its results should not be assumed to be as generalizable. It would be worthwhile to see how the results might differ if Hong Kong and Mainland China 
(or non-Chinese-speaking regions) were included, and/or if the sample of writings was expanded to include books and articles as well as dissertations. Conceptually, this kind of meta-analytic exercise could bring a range of meaningful insights to the future study of creativity.

Despite these limitations, however, the present meta-analytic study clearly shows that creativity as a topic has been widely investigated in three aspects or four levels. Through the lens of aspects, the category of process has been the most studied and that of traits is the least studied. It is probable that in the psychological literature on personality, creativity had been well documented by the early 1980s (Barron \& Harrington, 1981), and that the current mainstream focus is still on cognition (Hennessey \& Amabile, 2010; Runco, 2004). Accordingly, contemporary creativity research on Taiwan is more chiefly attuned to the process of how to improve creativity and of what impact creativity may have. Among the four levels, the individual still draws the lion's share of research attention as a unit of analysis. Interestingly, the results of the current study are similar, up to a point, to those of Wehner et al. (1991) and Kahl et al. (2009). When comparing the former's-North American sample from 1986, and the latter's North American sample from 2005-2007, and Taiwanese sample from 1993-2013, it is clear that some dimensions of creativity have been neglected by doctoral students altogether. For instance, there are almost no dissertations written on the cultures or products of creative traits (and in our case, there is no record of either; see Table 1).

This study also has made it clear that creativity is an important phenomenon across different disciplines, despite their isolation from one another. As shown in Table 2, most graduates in our sample who were interested in studying creativity were in the fields of education and business administration, a finding that chimes with previous studies (Kahl et al., 2009; Wehner et al., 1991). As far as research approach is concerned, quantitative and qualitative methodologies were equally popular; among them, correlational, quasi-experimental, and case study methods were the most frequently used in Taiwan. Taiwanese dissertations submitted between 1993 and 2013 reveal that the empirical quantitative rationale still outstrips other approaches in popularity in that country.

Major findings from my qualitative analysis indicate that creativity might serve to maximize both students' learning performance, and organizational survival. A positive profile of creativity was illustrated by these dissertations, in which "creativity" and "innovation" seem to be used interchangeably, based on the results of word counting. It is widely believed that fluency, flexibility, originality, and elaboration are four important ingredients of creative thinking (Guilford, 1956; Kim, 2011; Runco \& Acar, 2012). These concepts, however, as demonstrated by word counting of abstracts, seem to be undervalued or at least understudied. On the other hand, it is possible that Taiwanese researchers have a tendency to describe creativity as a holistic concept rather than utilizing several sub-constructs to explain it. It is also worth noting that "flexibility" and "fluency" were more important concepts in our sample than "originality" and "elaboration". Although several Western scholars have argued that originality is the crux of creativity (Boden, 1990; Barron, 1963; Runco \& Jaeger, 2012), Taiwanese students of creativity, as influenced by Chinese culture, would appear to have slightly different implicit theories of creativity. This observation echoes those of other 
cross-cultural studies (Lubart, 1990; Mouchiroud \& Lubart, 2002; Niu \& Sternberg, 2001), all of which found that Eastern and Western peoples possess a different conception of creativity to some extent. This idea deserves more attention from future cross-cultural studies, which might help to untangle various nuances in the perception of creativity in different parts of the world.

In summary, this study has used a qualitative meta-analytic approach to investigate Taiwanese researches attitudes toward and perceptions of creativity. It is hoped that closer examination of the extant intellectual corpus will draw even more attention to the issue of creativity development in Taiwan. From our sample, it is clear that the notion of creativity is treated not only as a means but as an end. Although a number of doctoral students follow frameworks and measurements proposed and developed by Western scholars to investigate creativity in Taiwanese contexts, several authors in our sample employ a different path that focuses on Taiwan's unique culture and industrial profile. This direction is especially promising. It is hoped that this article's examination of Taiwanese dissertations will stimulate other investigators to conduct in-depth studies for the better understanding of local creativity development and related issues.

\section{Implications}

The findings of this study, as discussed above, carry two general implications. First, as Niu and Sternberg (2003) recommend, teachers should take the lead in encouraging students to challenge norms, reflect critically on the curriculum, think imaginatively, and increase their involvement in creative self-exploratory activities. Second, the development of creative industries seems to be an important arena that not only reflects Taiwan's unique culture, but also provides a proper position from which to face globalization. In this sense, government should promote the brand "Made in Taiwan" to other nations by rediscovering Taiwanese grassroots culture and then transforming this into tangible creative products or intangible services.

\section{Conclusion}

The government of Taiwan should view the development of creative potential as an important agenda for its subjects. In the near future, we may see the fulfillment of Florida's (2002) prediction, that the "creative class" will have a substantial impact on society (p. 8). If so, education will play an important role in facilitating this development. All stakeholders appear to see educators as the driving force in the actualization of creative-potential-development programs and activities. Therefore, as Torrance (1995) suggested, educators "must somehow learn to reward creative thinking" (p. 65) in the classroom. Moreover, "we need to know how to structure learning environments to promote the development of creative-thinking skills. We need to know how information should be presented to promote creative thought" (Mumford, 1995, p. 410).

\section{References}

Barron, F. (1963). Creativity and psychological health: Origins of personal vitality and creative freedom. Princeton, NJ: D. Van Nostrand. 
Barron, F., \& Harrington, D. M. (1981). Creativity, intelligence, and personality. Annual $\begin{array}{llll}\text { Review of Psychology, 32(1), } & \text { 439-476. }\end{array}$ http://dx.doi.org/10.1146/annurev.ps.32.020181.002255

Boden, M. A. (1990). The creative mind: Myths \& mechanisms. London, UK: George Weidenfeld and Nicolson.

Fisher, B. J., \& Specht, D. K. (1999). Successful aging and creativity in later life. Journal of Aging Studies, 13(4), 457-472. http://dx.doi.org/10.1016/S0890-4065(99)00021-3

Flood, M., \& Scharer, K. (2006). Creativity enhancement: Possibilities for successful aging. $\begin{array}{llll}\text { Issues in Mental Health } & \text { 939-959. }\end{array}$ http://dx.doi.org/10.1080/01612840600899832

Florida, R. (2002). The rise of the creative class and how it's transforming work, leisure, community, and everyday life. New York, NY: Basic Books.

Fontenot, N. A. (1993). Effects of training in creativity and creative problem finding upon business people. Journal of Social Psychology, 133(1), 11-22. http://dx.doi.org/10.1080/00224545.1993.9712114

Guilford, J. P. (1956). The structure of intellect. Psychological Bulletin, 53(4), 267-293. http://dx.doi.org/10.1037/h0040755

Hennessey, B. A., \& Amabile, T. M. (2010). Creativity. Annual Review of Psychology, 61(1), 569-598. http://dx.doi.org/10.1146/annurev.psych.093008.100416

HyperRESEARCH (Version 3.5) [Computer software]. (2013). Randolph, MA: Researchware.

Kahl, C. H., da Fonseca, L. H., \& Witte, E. H. (2009). Revisiting creativity research: An investigation of contemporary approaches. Creativity Research Journal, 21(1), 1-5. http://dx.doi.org/10.1080/10400410802633350

Kim, K. H. (2011). The creativity crisis: The decrease in creative thinking scores on the Torrance Tests of Creative Thinking. Creativity Research Journal, 23(4), 285-295. http://dx.doi.org/10.1080/10400419.2011.627805

Leech, N. L.,\& Onwuegbuzie, A. J. (2007). An array of qualitative data analysis tools: A call for data analysis triangulation. School Psychology Quarterly, 22(4), 557-584. http://dx.doi.org/10.1037/1045-3830.22.4.557

Lubart, T. I. (1990). Creativity and cross-cultural variation. International Journal of Psychology, 25(1), 39-59. http://dx.doi.org/10.1080/00207599008246813

Ma, H. H. (2006). A synthetic analysis of the effectiveness of single components and packages in creativity training programs. Creativity Research Journal, 18(4), 435-446. http://dx.doi.org/10.1207/s15326934crj1804_3

Magyari-Beck, I. (1990). An introduction to the framework of creatology. Journal of Creative 
Behavior, 24(1), 151-160. http://dx.doi.org/10.1002/j.2162-6057.1990.tb00537.x

Ministry of Education (2002). White paper on creative education: Establishing a republic of creativity for Taiwan. Taipei: Author.

Moneta, G. B., Amabile, T. M., Schatzel, E. A., \& Kramer, S. J. (2010). Multirater assessment of creative contributions to team projects in organizations. European Journal of Work and Organizational Psychology, 19(2), 150-176. http://dx.doi.org/10.1080/13594320902815312

Mouchiroud, C., \& Lubart, T. (2002). Social creativity: A cross-sectional study of 6- to 11-year-old children. International Journal of Behavioral Development, 26(1), 60-69. http://dx.doi.org/10.1080/01650250042000591

Mumford, M. D. (1995). Situational influences on creative achievement: Attributions or interactions? Creativity Research Journal, 8(4), 405-412. http://dx.doi.org/10.1207/s15326934crj0804_7

Niu, W., \& Sternberg, R. J. (2001). Cultural influences on artistic creativity and its evaluation. $\begin{array}{llll}\text { International Journal of 225-241. } & \text { Psychology, }\end{array}$ http://dx.doi.org/10.1080/00207590143000036

Niu, W., \& Sternberg, R. J. (2003). Societal and school influences on student creativity: The case of China. Psychology in the Schools, 40(1), 103-114. http://dx.doi.org/10.1002/pits.10072

Okuda, S. M., Runco, M. A., \& Berger, D. E. (1991). Creativity and the finding and solving of real-world problems. Journal of Psychoeducational Assessment, 9(1), 45-53. http://dx.doi.org/10.1177/073428299100900104

Runco, M. A. (2004). Creativity. Annual Review of Psychology, 55(1), 657-687. http://dx.doi.org/10.1146/annurev.psych.55.090902.141502

Runco, M. A., \& Acar, S. (2012). Divergent thinking as an indicator of creative potential. Creativity Research Journal, 24(1), 66-75. http://dx.doi.org/10.1080/10400419.2012.652929

Runco, M. A., \& Jaeger, G. J. (2012). The standard definition of creativity. Creativity Research Journal, 24(1), 92-96. http://dx.doi.org/10.1080/10400419.2012.650092

Scott, G., Leritz, L. E., \& Mumford, M. D. (2004). The effectiveness of creativity training: A quantitative review. Creativity Research Journal, 16(4), 361-388. http://dx.doi.org/10.1080/10400410409534549

Sierpina, M., \& Cole, T. (2004). Stimulating creativity in all elders: A continuum of interventions. Care Management Journals, 5(3), 175-182. http://dx.doi.org/10.1891/cmaj.2004.5.3.175

Torrance, E. P. (1995). Why fly? A philosophy of creativity. Norwood, NJ: Ablex.

Torrance, E. P., \& Presbury, J. (1984). The criteria of success used in 242 recent experimental studies of creativity. The Creative Child and Adult Quarterly, 9(4), 238-243. 


\section{Macrothink}

International Journal of Culture and History

ISSN 2332-5518 2014, Vol. 1, No. 2

Wehner, L., Csikszentmihalyi, M., \& Magyari-Beck, I. (1991). Current approaches used in studying creativity: An exploratory investigation. Creativity Research Journal, 4(3), 261-271. http://dx.doi.org/10.1080/10400419109534398

Zhou, J., \& George, J. M. (2001). When job dissatisfaction leads to creativity: Encouraging the expression of voice. Academy of Management Journal, 44(4), 682-696. http://dx.doi.org/10.2307/3069410

\section{Copyright Disclaimer}

Copyright for this article is retained by the author(s), with first publication rights granted to the journal.

This is an open-access article distributed under the terms and conditions of the Creative Commons Attribution license (http://creativecommons.org/licenses/by/3.0/). 